\title{
المعارف المكتسبة لتعرض الزراع لبرنامج إرشادي في مجال زراعة محصول الفراولة بمحافظة القليوبية

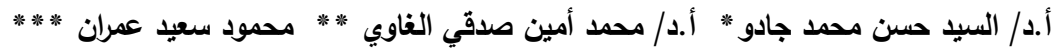

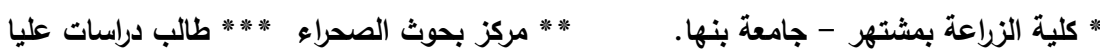 \\ Corresponding author: alsayed.mustafa@ @fagr.bu.edu.eg
}

المستخلص

استهدف البحث دراسة المعارف المكتسبة لتعرض الزراع لبرنامج إرشادي في مجال زراعة محصول الفراولة بمحافظة القليوبية، وذلك من

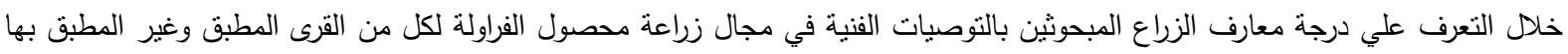

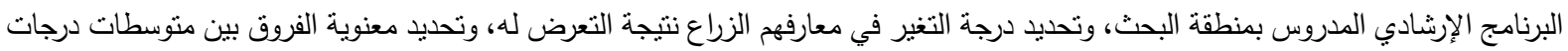

وتم إجراء البحث بمركزي شبين القناطر ، وطوخ باعتبارهما أكبر مركزين من حيث المساحة التي تزرع بهما الفراولة بالمحافظة، وتم تحديد

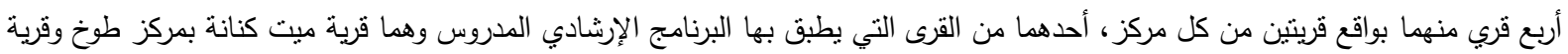

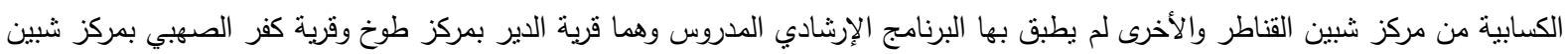

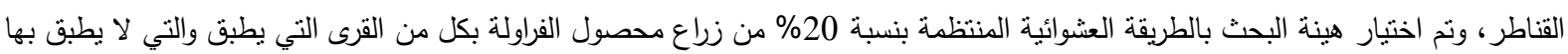

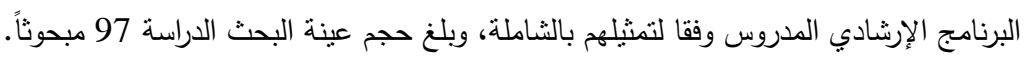
وجمعت بيانات البحث عن طريق المقابلة الثخصية للمبحوثين بواسطة استمارة استيان خلال الثهور الثلاث الأخيرة من عام 2019،

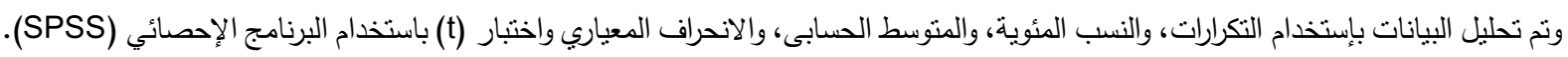

وتمثلت أهم نتائج البحث فيما يلي: • بلغ المتوسط الكلي لمتوسطات درجات معارف زراع محصول الفراولة المبحوثين بالقريتين المطبق بهما البرنامج الإرشادي الدرروس1.49 درجة. • بلغ المتوسط الكلي لمتوسطات درجات معارف زراع محصول الفراولة المبحوثين بالقريتين غير المطبق بهما البرنامج الإرشادي المدروس1.14 درجة.

• بلغ متوسط الفرق بين منوسطات درجات معارف زراع محصول الفراولة المبحوثين بالقرى المطبق وغير المطبق بها البرنامج الإششادي 0.37 درجة، لصالح العينة المطبق بها البرنامج الإرشادي المدروس.

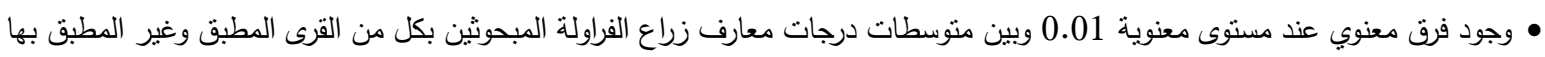

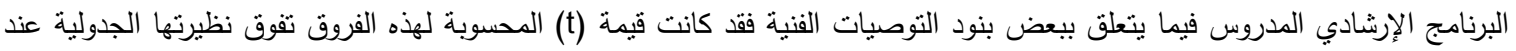

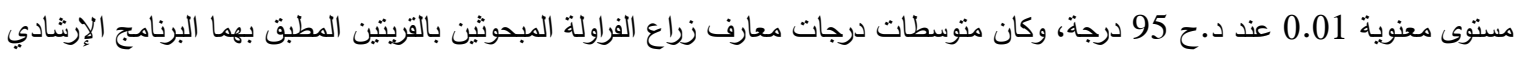
المدروس كانت أكبر من مثيلاتها لدى زراع الفراولة المبحوثين بالقريتين غير المطبق بهما البرنامج الإرشادي المدروس.

• وجود فرق معنوي عند مستوى معنوية 0.05 بين متوسطات درجات معارف زراع الفراولة المبحوثين بكل من القرى المطبق وغير المطبق بها

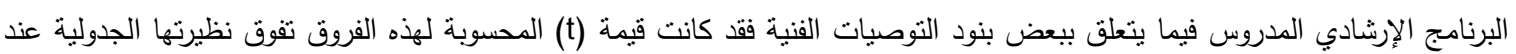

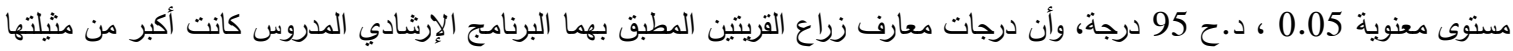
لزراع القريتين غير المطبق بهما البرنامج الإرشادي.

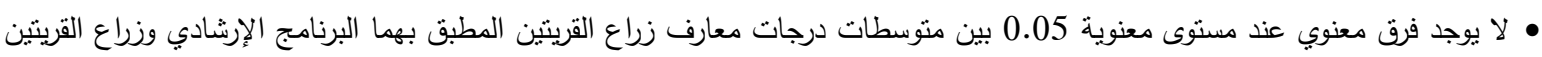

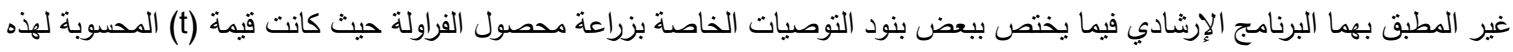

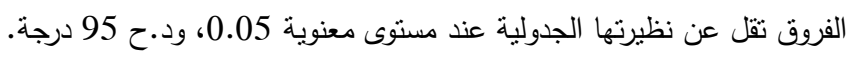

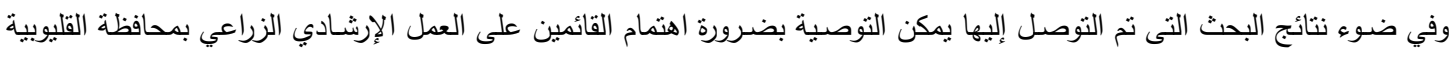

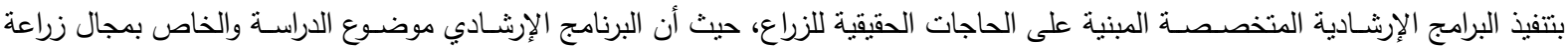

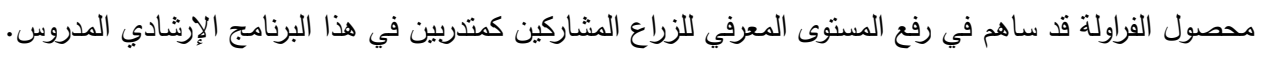


المقدمة والمشكلة البحثية

تعتبر الزراعة أحد المجالات الاقتصادية الهامة التي تبنت فيها مصر سياسة التحرر والإصلاح الاقتصادي، وحتى يكتب لمصر النجاح في تطبيق هذه السياسة فإن الأمر يستلزم تعليم المزارعين كل ما هو جديد وملائم لبيئتهم وإمكانياتهم العقلية والمادية والمالية.

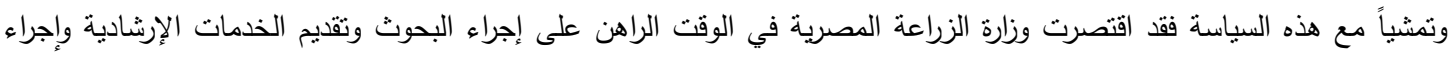
الدراسات الاقتصادية وتوفير البيانات الاحصائية، وذلك من خلال التعاون الوثيق بين ثلاثة محاور رئيسية هي: البحوث الزراعية والإرشاد وجماهير المسترشدين (سليم ، 1995: ص 149). هذا وأصبحت التتمية وتحديث الزراعة المصرية هي المحور الأساسي لاهنمام المسئولين عن القطاع الزراعي رغبة في رفع مستوى المعيشة وتحقيق حياة أفضل لسكان الريف، ولكي يتم ذلك كان من الضروري وضع نواتج التقدم التكنولوجي ونتائج البحوث الزراعية موضع التطبيق

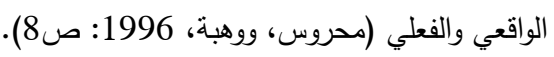
وانطلاقا من ذلك فإنه من المنطقي توقع حدوث تغييرات في النظم والمعلومات والممارسات الزراعية الحالية للتكيف مع هذا المناخ وهذه الفلسفة الجديدة. فقد ذكر "قثطة" (قشطة، 1996 : ص، ص صل 23 ، 24) أن التغييرات السلوكية هي الهدف النهائي للنشاط الإرشادي ولا يمكن

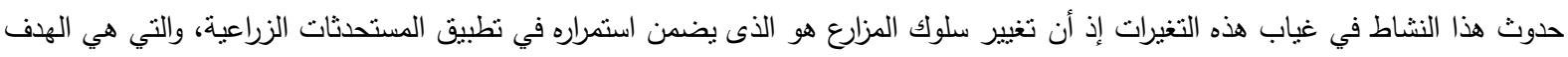
الأساسي للخدمة الإرشادية الزراعية ولا تقتصر على نقل وتوصيل هذه المستحدثات إلى الزراع فقط بل لابد من تطبيق هذه المستحدثات في إطار

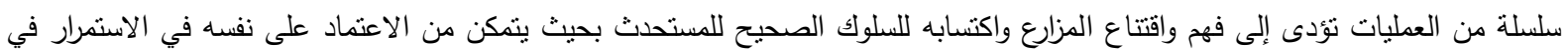
التطبيق مستقبلاً.

ويقوم جهاز الإرشاد الزراعى عن طريق الإدارة المركزية للإرشاد الزراعي بوضع عدد كبير من البرامج الإرشادية الزراعية في مجالات

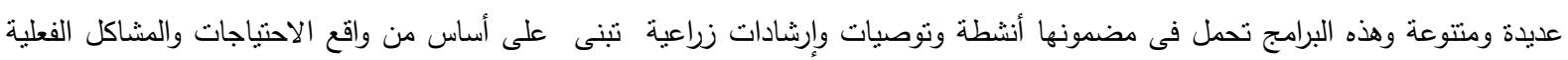
للزراع، بما يؤدى إلى حصولهم على إنتاج زراعي مرتفع ودرجة جودة عالية حتى تمكنهم ممن التصدي للمنافسة القوبة.

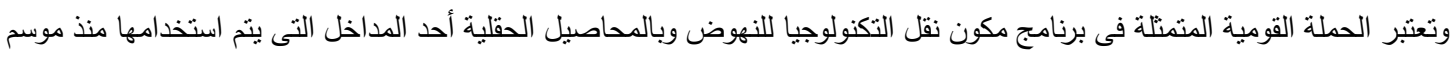
1982/ 1983، ويمكن النظر إلى هذه الحملات على أنها علاقة متبادلةبين البحث والإرشاد الزراعى والمزارعين حيث يتم فيها توحيد جهود الباحثين والعالمين بالإرشاد الزراعى لنقل التوصيات الفنية الصالحة للنطبيق إلى المزارعين من خلال دراسة الموقف والتعرف على مشكلات زراعة المحاصيل الحقلية، وجمع البيانات اللازمة وتحديد الأهداف لتخطيط برنامج الحملة، وأيضاً وضع وتنفيذ خطة العمل لبرنامج الحملة، وتقييم الأنشطة الإرشادية

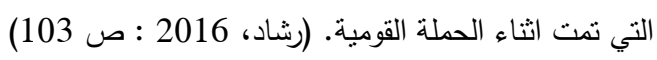
وتعتبر محافظة القليوبية أحد المحافظات الرئيسية المنتجة لمحاصيل الخضر في مصر وذلك لقربها من محافظتي القاهرة والجيزة وقربها من الأسواق الرئيسية الكبرى مثل سوق العبور ، حيث تمثل المساحة المزروعة بالخضر بالمحافظة حوالي 15860 فدان، وتبلغ مساحة الفراولة منها 4141 فدان من إجمالي مساحة الخضر بالمحافظة وهي تمثل نسبة 26\% نقريبا خلال نفس العام الزراعي 2018 / 2019 (الادارة المركزية

$$
\text { للاقتصاد الزراعي، 2020)، }
$$

وللفراولة فوائد عديدة، من أهمها: تحتوي القليل من السعرات الحرارية. حيث أن 100 غرام من الفراولة الطازجة تحتوي على 32 سعرة حرارية فقط. كما أنها تتري غذائنا بالفيتامينات والمعادن. لهذا فإن إضافة الفراولة الطازجة إلى النظام الغذائي اليومي في شكلها الطبيعي، كإضافتها لهريا

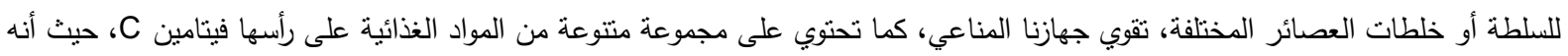

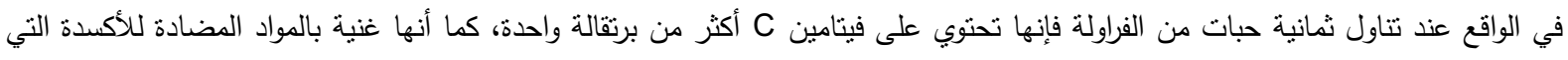

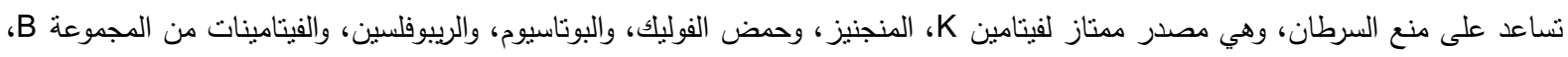
والنحاس، والماغنيسيوم والاوميجا 3، وهي أيضا غنية بالألياف القابلة للذوبان التي تساعد في خفض LDL المعروف أيضا باسم "الكولسترول السيىء". تساعد الألياف على تتظيم عملية الهضم وتقلل من خطر الاصابة بأمراض القلب والأوعية الدموية، كما ان الفراولة تحسن وظائف الأوعية الدموية

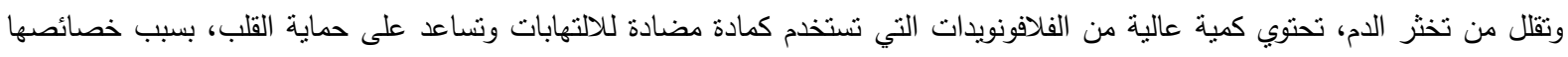
المضادة للالتهابات، فهي فعالة أيضاً ضد التهاب المفاصل. (كتيب المشروع التدريبي علي منظومة التكويد للتصدير، شركة بشاير وقسم المكافحة

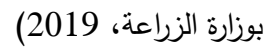

ومن هنا تبرز أهمية وجود دور إرشادي زراعي فعال وذلك من خلال بناء برامج للإرشاد الزراعي في مجال زراعة محصول الفراولة،

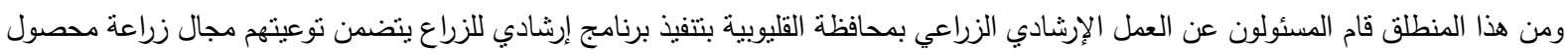
الفراولة، ونظراً لهذه الأهمية فإن الأمر يتطلب إجراء هذا البحث بغرض فئن فياس المعارف المكتسبة لتعرض الزراع لبرنامج إرشادي في مجال زراعة محصول الفراولة بمحافظة القليوبية. 
أهداف البحث

بناء على المشكلة البحثية سالفة الذكر أمكن صياغة الأهداف البحثية التالية: 1. التعرف علي درجة معارف الزراع المبحوثين بالتوصيات الفنية في مجال زراعة محصول الفراولة لكل من القرى المطبق وغير المطبق بها البرنامج الإرشادي المدروس بمنطقة البحث. 2. تحديد درجة التغير في معارف الزراع المبحوثين بالتوصيات الفنية في مجال زراعة محصول الفراولة نتيجة التعرض للبرنامج الإرشادي المدروس بمنطقة البحث. 3. تحديد معنوية الفروق بين منوسطات درجات معارف الزراع المبحوثين بالتوصيات الفنية في مجال زراعة محصول الفراولة لكل من القرى المطبق وغير المطبق بها البرنامج الإرشادي المدروس بمنطقة البحث.

الطريقة البحثية التعريفات الإجرائية لبعض المصطلحات المستخدمة في البحث: 1- القرى المطبق بها البرنامج الإرشـادى: يقصـــ بها القرى التي خطط لها برنامج ارشــادي للنهوض بمحصــول الفراولة يزداد فيها درجة تكثيف

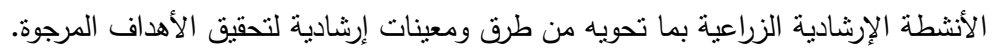

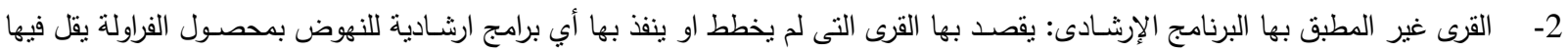
درجة تكتيف الأنشطة الإرشادية الزراعية.

فروض البحث يمكن صياغة الفرض النظري لهذا البحث كما يلي: توجد فروق معنوية بين متوسطات درجات معارف الزراع المبحوثين بالتوصيات الفنية في مجال زراعة محصول الفراولة لكل من القرى المطبق وغير المطبق بها البرنامج الإرشادي المدروس بمنطقة البحث.

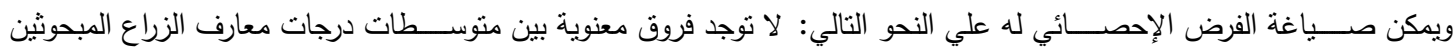
بالتوصيات الفنية في مجال زراعة محصول الفراولة لكل من القرى المطبق وغير المطبق بها البرنامج الإششادي المدروس بمنطقة البحث.

إختيار منطقة الدراسة والبرنامج الإششادي المدروس اختيرت محافظة القليوبية لإجراء هذه الدراسة بها، نظراً لكونها إحدى المحافظات الرئيسية المنتجة لمحصول الفراولة في جمهورية مصر العربية، والتي نفذ بها البرنامج الإرثـادي الزراعي "من المزرعة إلي التصــدير" والذي طبق علي زراع محصــول الفراولة بالمحافظة، وتحقيقاً لهدف

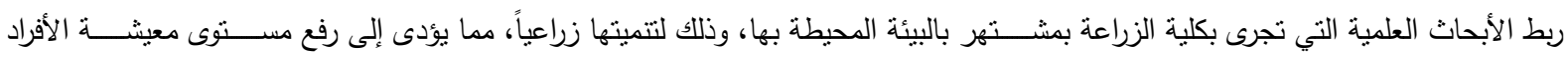
المحليين بها وتحقيق الرفاهية لهم، كما أنها الموطن الأصـلي للباحث مما يسـاعد على توفير الوقت والجهد والتسـهيلات التي تتطلبها إجراء الدراسـة

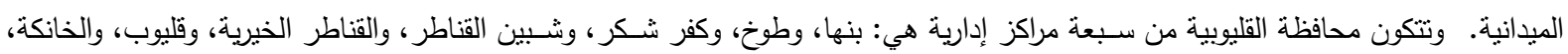
ولإجراء هذه الدراسة تم أخذ أحد البرامج الإرشادية التي نفذت بالمحافظة وهو برنامج "من المزرعة إلي التصدير" والذي طبق علي محصول الفراولة

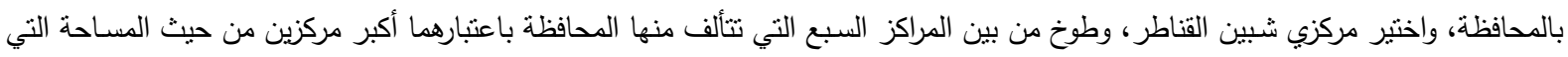

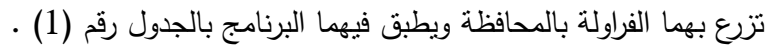

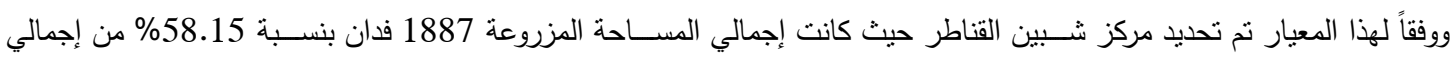
المسـاحة المزروعة بمحصـول الفراولة على مسـتوى المحافظة، ومركز طوخ حيث بلغت المسـاحة المزروعة به 1204 فدان بنسبة 37.15 \% من

إجمالي المساحة المزروعة بمحصول الفراولة بالمحافظة كما توضحها البيانات الواردة بالجدول رقم (1) . جدول رقم 1 ـ إجمالي مساحات الفراولة بمحافظة القليوبية خلال الموسم الزراعي 2019/2018

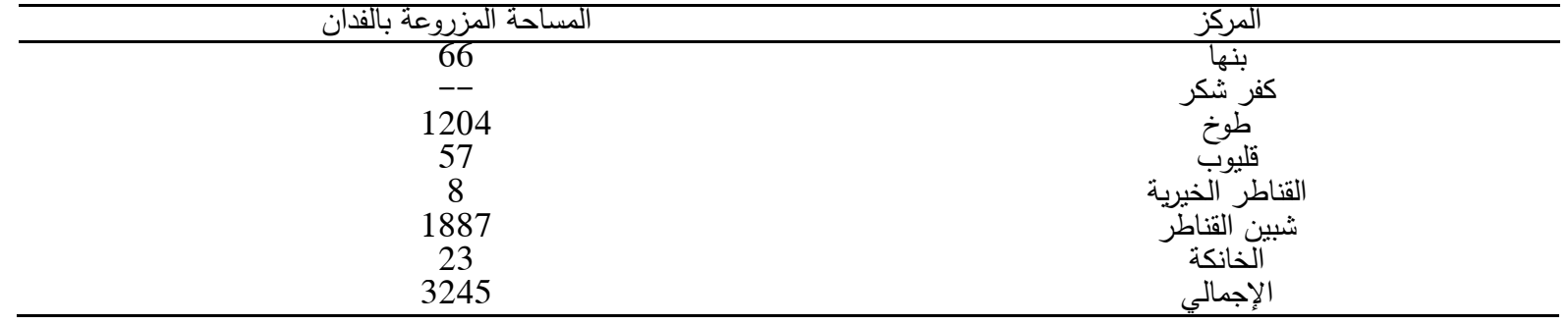


وأخيراً تم تحديد أربع قري من المركزين سـالفي الذكر السـابق تحديدهما بنفس المعيار السـابق بواقع قريتين من كل مركز ، أحدهما من

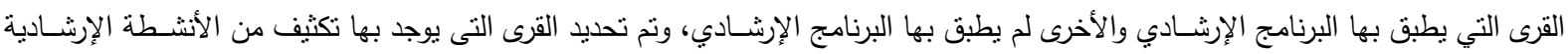

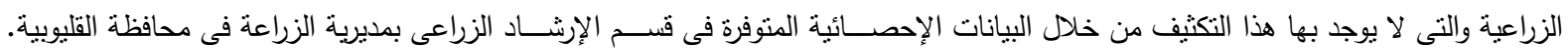

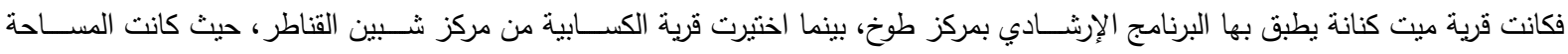

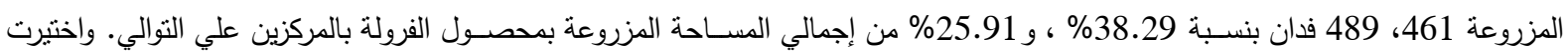
قريتان لا يطبق بهما البرنامج الإرشادي بنفس المركزين، فكانت قرية الدير بمركز طوخ، وقرية كفر الصـبي بمركز شبين القناطر ، وكانت المساحة المزروعة بهما 442 ، 327 فدان بنسبة 36.71 \% ، 17.33\% من إجمالي المساحة المزروعة بمحصول الفراولة بالمركزين علي التوالي.

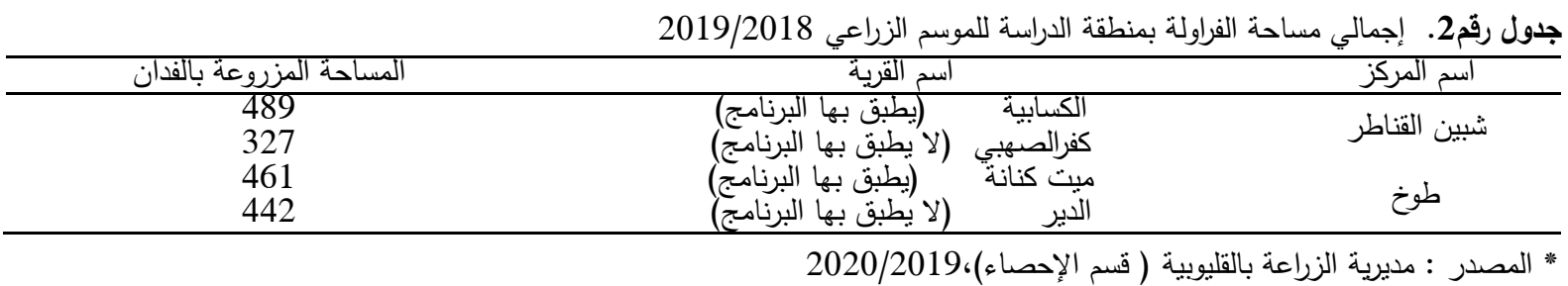

شاملة وعينـة البحث

تم اختيار أربع عينات بالطريقة العشـوائية المنتظمة بنسبة 20 \% من زراع محصـول الفراولة بكل من القرى التي يطبق والتي لا بطبق

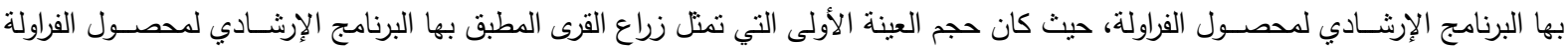

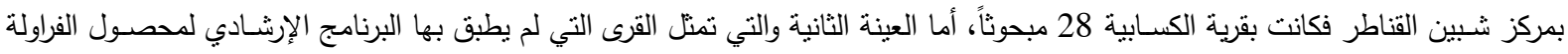

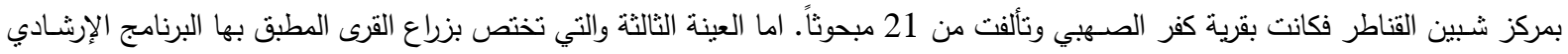

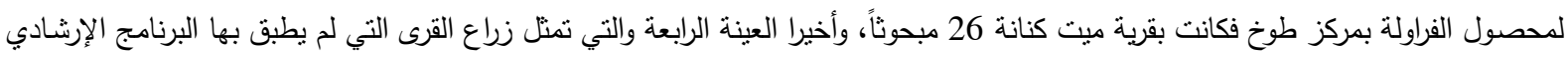

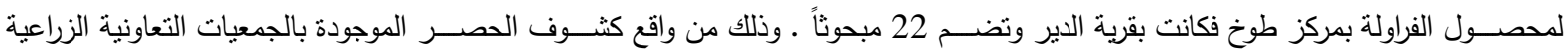

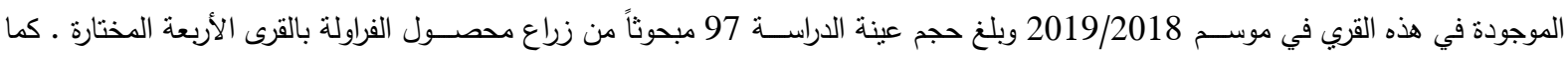

أوضحت بيانات الدراسة بالجدول رقم (3).

\begin{tabular}{|c|c|c|c|c|c|}
\hline$\%$ & العينة & عدد الحائزين & اسم القرية & & اسم المركز \\
\hline $\begin{array}{l}20 \\
20\end{array}$ & $\begin{array}{l}28 \\
21\end{array}$ & $\begin{array}{l}140 \\
109\end{array}$ & (لا بطبق بها البرنامج) & كفرالصسابية & شبين القناطر \\
\hline $\begin{array}{l}20 \\
20\end{array}$ & $\begin{array}{l}26 \\
22\end{array}$ & $\begin{array}{l}132 \\
110\end{array}$ & 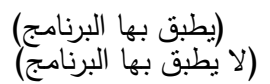 & ميت كنانة & طوخ \\
\hline 19.75 & 97 & 491 & & المجموع & \\
\hline
\end{tabular}

*2020/2019،المصدر : مديرية الزراعة بالقليوبية (قسم الإحصاء) *

مصادر وطريقة وأدوات جمع البيانات

اعتمد البحث على مصــرين للحصــول على البيانات اللازمة لتحقيق أهدافها أولهما: المصـادر الثانوية والتي كانت متمنلة في كل من: قسم الإحصـاء بالإدارة المركزية للاقتصـاد الزراعي بوزارة الزراعة، وقسـم الإحصـاء بمديرية الزراعة ببنها، والوحدة الزراعية بمركزي شبين القناطر وطوخ، وذللك للحصــول على البيانات المتعلقة بتحديد منطقة الدراسـة واختيار عينة الدراســة والحصــول على المعلومات والتوصـيات الفنية المتعلقة بمحصول الفراولة .

أما ثاني هذه المصـادر فيتعلق بالبيانات التي نت جمعها من مصـادرها الأولية عن طريق المقابلة الثخصية للمبحوثين بواسطة استمارة

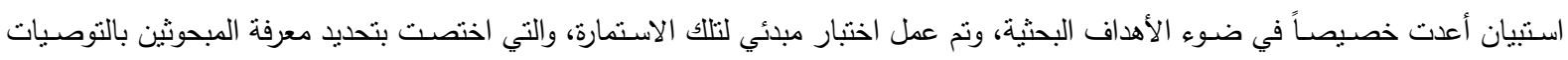
الفنية التي يوصـي بها الإشــاد الزراعي، والتي اعتمدت في حصـرها على مجموعة من النشـرات الإرشـادية التي تحتوي على التوصـيات الفنية

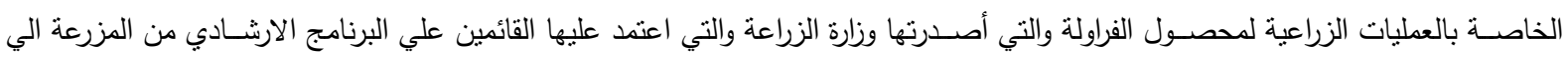
التصدير في تقديم التوصيات الارشادية لهولاء الزراع. (الادارة المركزية للارشاد الزراعي، وزارة الزراعة واستصلاح الاراضي 2019). 
وقد مر إعداد استمارة الاستيليان بعدة مراحل حتى بلغت شـكاها النهائي، حيث بدأت بقيام الباحث بزيارة لبعض مناطق إنتاج محصـول

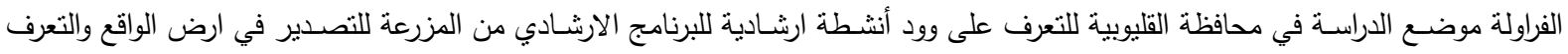

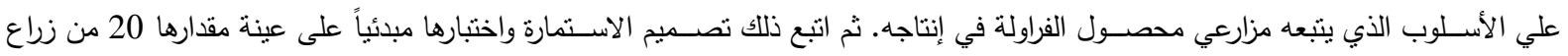

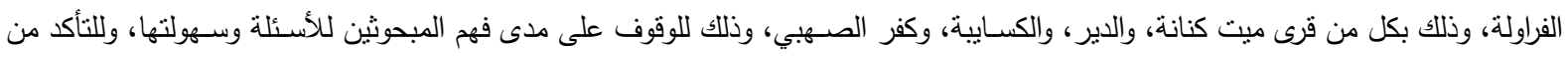

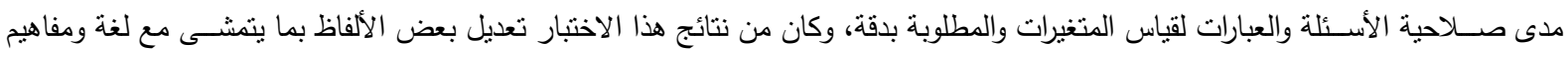

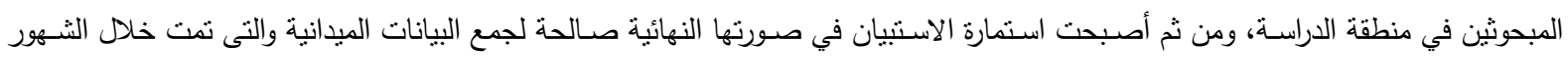

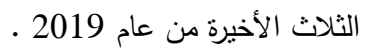

تم أستخدام أساليب التحويل الرقمي للإجابات على أسئلة استمارة الدراسة بما يجعلها صالحة للنحليل الإحصائي، لكي تحقق البيانات التي

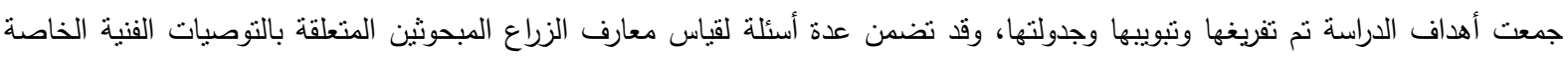

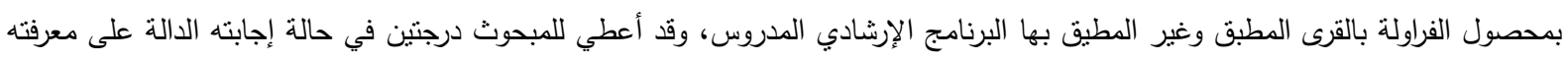

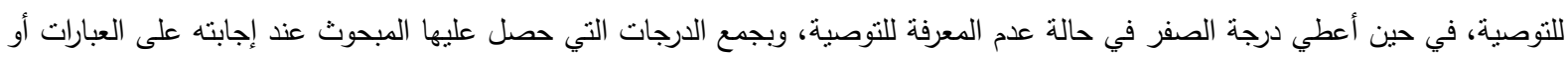

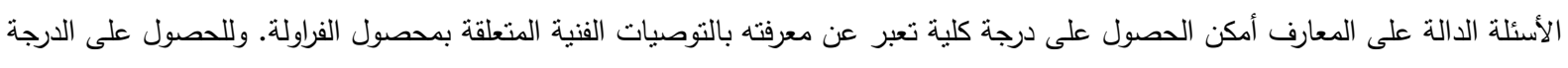

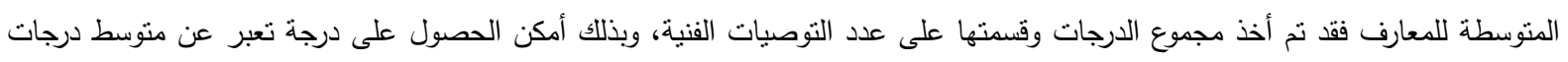

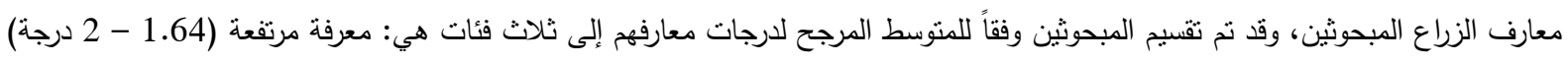

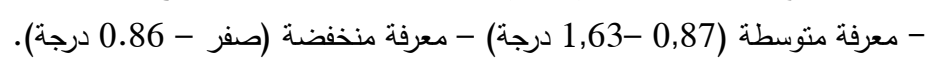

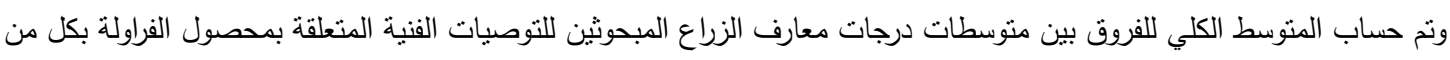

القرى المطبق وغير المطبق بها البرنامج الإرشادي (بقسمة مجموع الفروق بين المتوسطات على عددهم).

أدوات التحليل الإحصائي

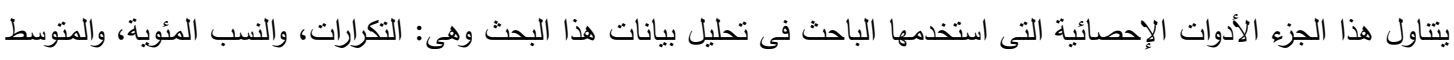

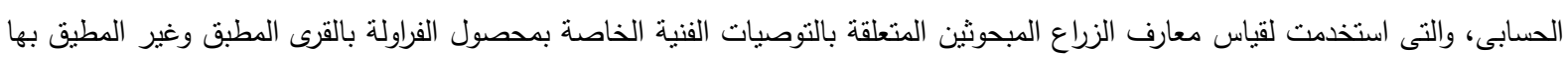

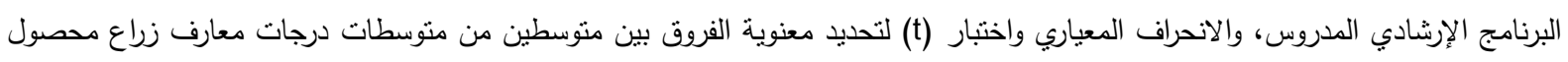

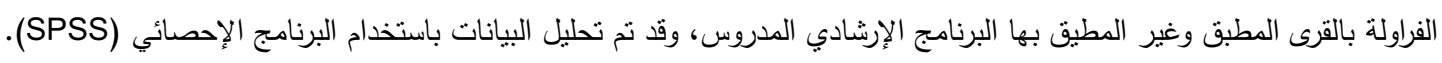

\section{التعرف علي درجة معارف الزراع المبحوثين بالتوصيات الفنية في مجال زراعة محصول الفراولة لكل من القرى المطبق وغير المطبق بها البرنامج} الإرشادي المدروس بمنطقة البحث.

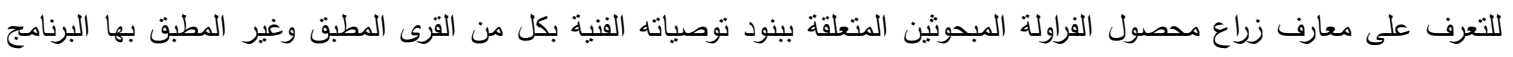

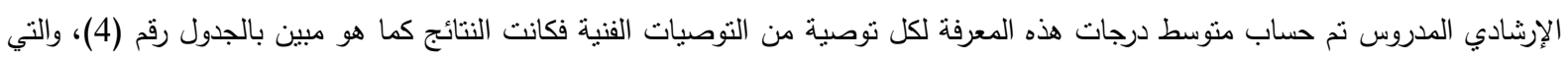

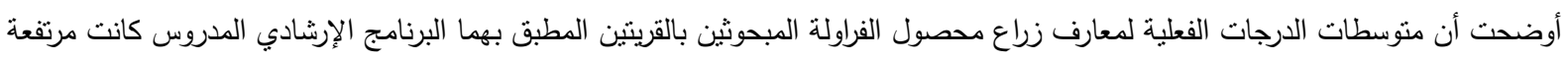

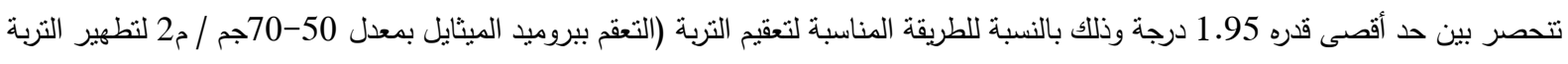

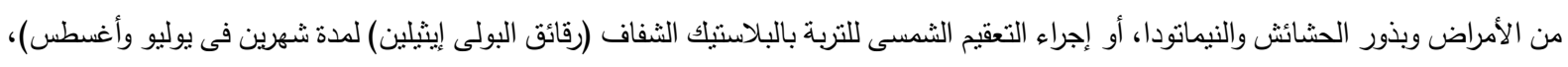

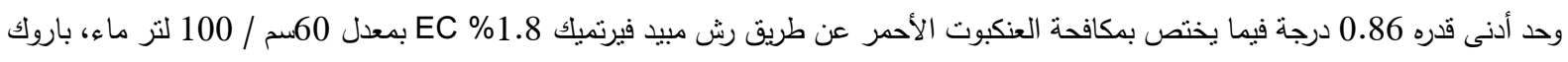

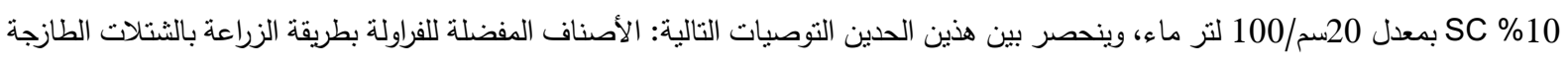

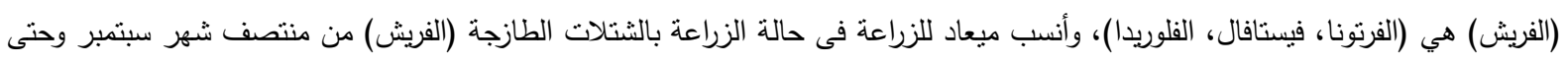

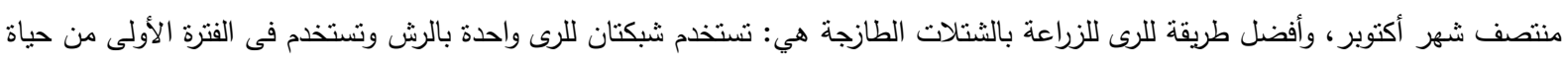

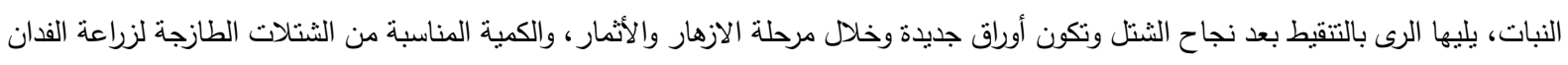

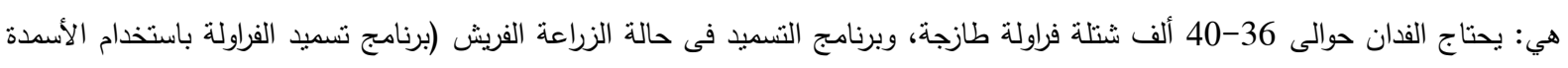

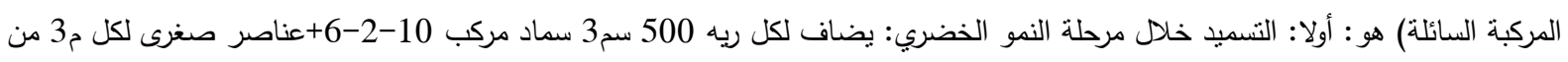


مياه الري. ثانبا: التسميد خلال مرحلة الازهار : تضاف لكل ريه500 سم3 سماد مركب 10-4-8+عناصر صغرى لكل متر مكعب لمياه الري. ثالثا: النسميد خلا مرحلة الإثمار : يضاف لكل ريه 500 سم3 سماد مركب 8-2-10+عناصر صغيل صغرى لكل م3 من مياه الري. وأفضل وسيله لمكافحة

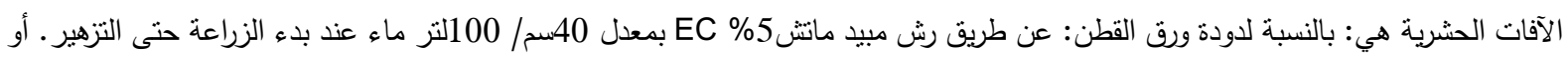
يتم رش بمبيد دايبل×2 بمعدل 75جم/100 لتر ماء عند بداية عقد الثمار • بالنسبة لأعفان الثمار : رش النباتات أثثاء التزهير والعقد بالمبيدات الأتية

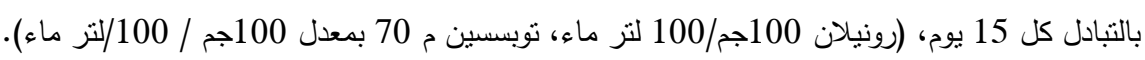
كما تبين أن متوســـات الدرجات الفعلية المنوســة لمعارف زراع الفراولة المبحوثين بالقريتين المطبق بهما البرنامج الإرشــادي المدروس تتحصـر بين حد أقصـى قدره 1.59 درجة، وحد أدنى قدره 1.23 درجة فيما يختص بثلاث توصـيات وهي كل من: الأصــناف المفضـلة للفراولة بطريقة الزراعة بالثتلات الطازجة (الفريش) هي (الفرنونا، فيستافال، الفلوريدا)، وأنسب ميعاد للزراعة فى حالة الزراعة بالثتنات الطازجة (الفريش)

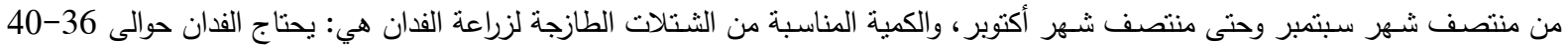
ألف شتلة فراولة طازجة.

بينما كانت منتوسطات الدرجات الفعلية المنخفضة لمعارف الزراع المبحوثين بالقريتين المطبق بهما البرنامج الإرشادي المدروس تتحصر بين حد أقصى 1.22 درجة، وحد أدنى قدره 0.86 درجة فيما يختص بثلاث توصيات وهي كل من: التسميد خلال مرحلة الازهار : تضاف لكل ريه 500 سم3 سماد مركب10-4-8+عناصر صغرى لكل منز مكعب لمياه الري، والتسميد خلال مرحلة الإثمار : يضاف لكل ريه 500 سم3 سماد

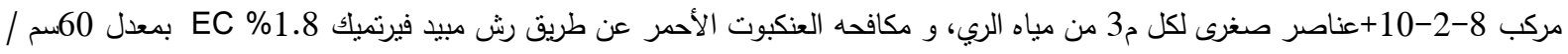
100 لتر ماء، باروك 10\% مC بمعدل 20 مسم /100 لتر ماء.

وبصـفة عامة فقد بلغ المتوســ الكلي لمتوسـطات درجات معارف زراع محصــول الفراولة المبحوثين في القريتين المطبق بهما البرنامج الإرشـادي المدروس 1.49 درجة. بما يعني أن درجات معارف زراع محصــول الفراولة المبحوثين كانت منوسـطة وذلك في القربتين المطبق بهما البرنامج الإرشادي المدروس.

أما بالنسبة لمتوسطات الدرجات الفعلية لمعارف زراع محصول الفراولة المبحوثين بالقريتين غير المطبق بهما البرنامج الإرشادي المدروس

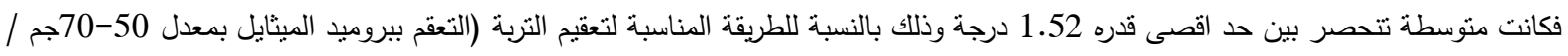
م2 لنطهير النربة من الأمراض وبذور الحشائش والنيماتودا، أو إجراء التعقيم الثمسى للتربة بالبلاستيك الثفاف (رقائق البولى إيثيلين) لمدة شهرين

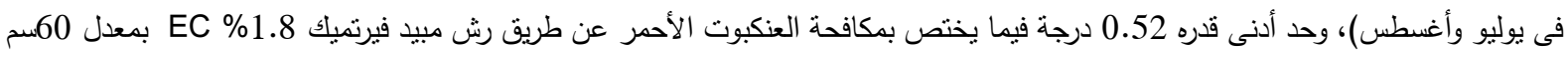
/ 100 لتر ماء، باروك 10\% SC بمعدل 20سم /100 لتز ماء، وينحصر بين هذين الحدين التوصيات التالية: الأصناف المفضلة للفراولة بطريقة الزراعة بالشتلات الطازجة (الفريش) هي (الفرتونا، فيستافال، الفلوريدا)، وأنسب ميعاد للزراعة في حالة الزراعة بالشتلات الطازجة (الفريش) من منتصف شهر سبتمبر وحتى منتصف شهر أكتوبر ، وأفضل طريقة للرى للزراعة بالثتلات الطازجة هي: تستخدم شبكتان للرى واحدة بالرش وتستخدم

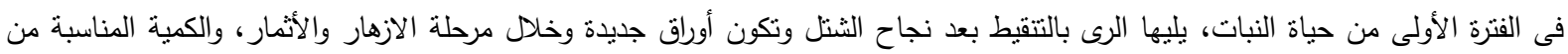
الثتلات الطازجة لزراعة الفدان هي: يحتاج الفدان حوالى 36-40 الفي شتلة فراولة طازجة، وبرنامج التسميد فى حالة الزراعة الفريش (برنامج تسميد

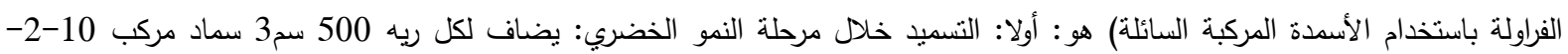

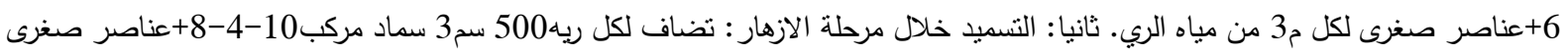

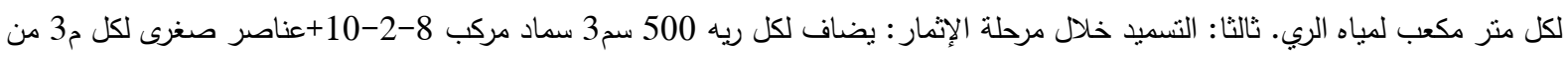

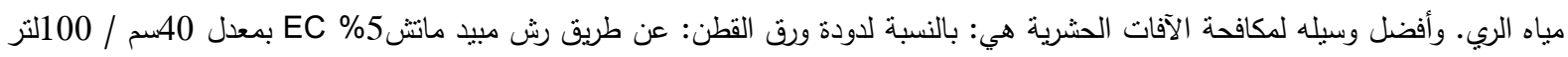

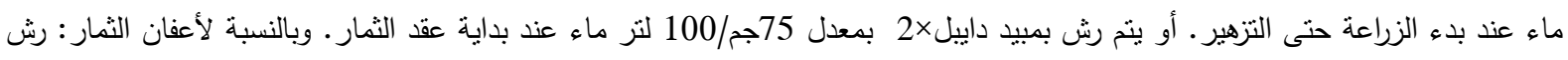

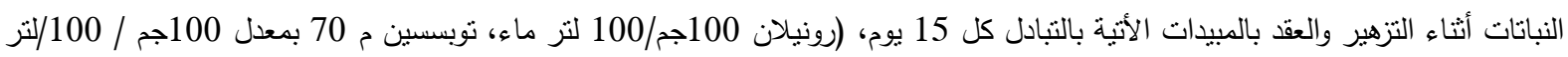

كما تنين أن متوســطات الدرجات الفعلية المتوســـة لمعارف زراع محصــول الفراولة المبحوثين بالقريتين غير المطبق بهما البرنامج الإرشادي المدروس تتحصر بين حد أقصى قدره 1.19 درجة، وحد أدنى قدره 0.85 درجة فيما بختص بثلاث توصيات وهي كل من: أنسب مبعاد

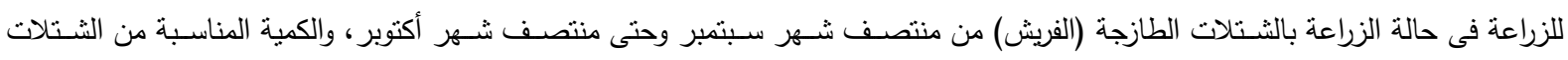

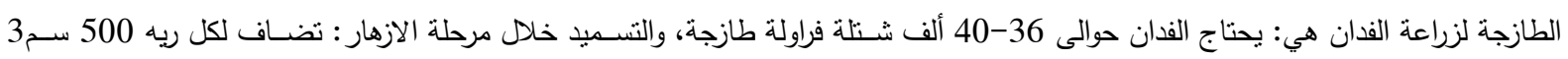
سماد مركب 10-4-8+عناصر صغرى لكل منز مكعب لمياه الري. بينما كانت متوسطات الدرجات الفعلية المنخفضة لمعارف زراع محصول الفراولة المبحوثين بالقريتين غير المطبق بهما البرنامج الإرشادي المدروس تتحصر بين حد أقصى 0.84 درجة، وحد أدنى قدره 0.52 درجة فيما يختص بتوصيتين وهما: التسميد خلال مرحلة الإثمار : يضاف لكل 
ريه 500 سم3 سماد مركب 8-2-10+عناصر صغرى لكل م3 من مياه الري، و مكافحه العنكبوت الأحمر عن طريق رش مبيد فيرتميك 1.8\% بماك

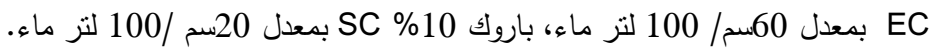

وبصـفة عامة فقد بلغ المتوسط الكلي لمتوسطات درجات معارف زراع محصـول الفراولة المبحوثين في القريتين غير المطبق بهما البرنامج

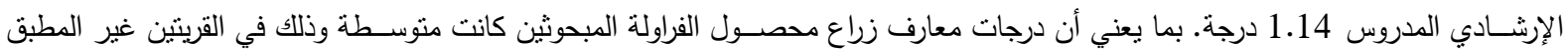
بهما البرنامج الإرثنادي المدروس.

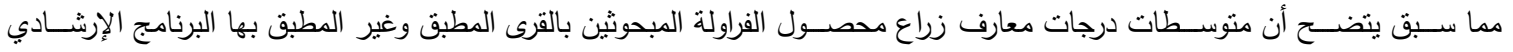

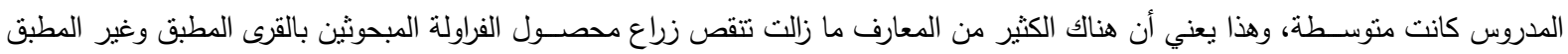

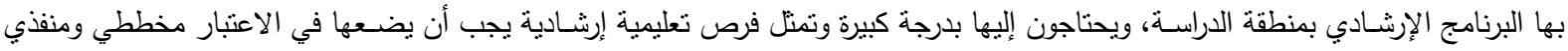

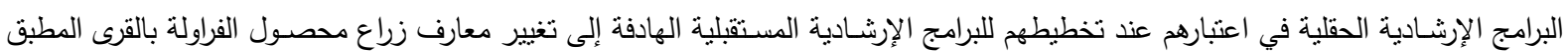

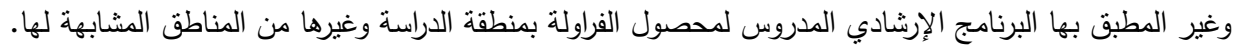

تحديد درجة التغير في معارف الزراع المبحوثين بالتوصيات الفنية في مجال زراعة محصول الفراولة نتيجة التعرض للبرنامج الإششادي المدروس

للتعرف على الفروق بين منوسطات درجات معارف زراع محصول الفراولة المبحوثين بالتوصيات الفنية بكل من القرى المطبق وغير المطبق

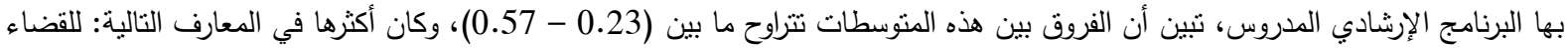

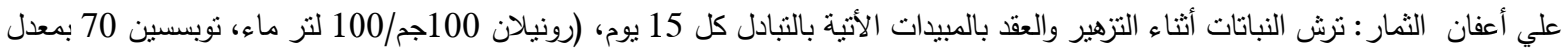

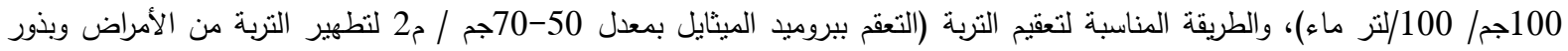

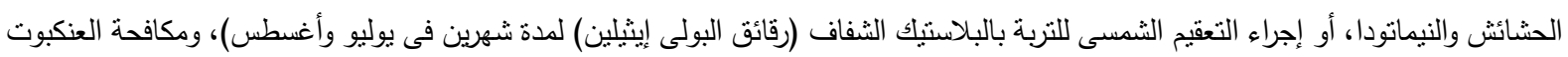

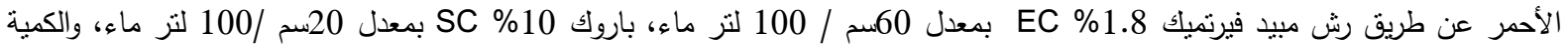

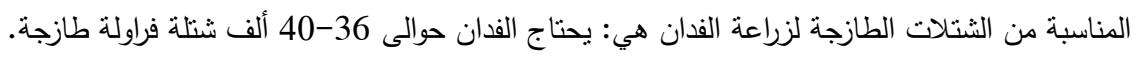

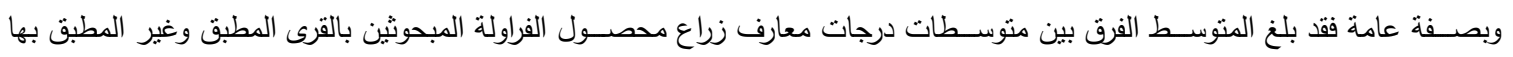
البرنامج الإرشـادي 0.37 درجة، بما بعني أن الفرق بين متوسطات درجات معارف زراع محصسول الفراولة المبحوثين بالقرى المطبق وغير المطبق المبق بها البرنامج الإرشادي المدروس كانت منذفضة.

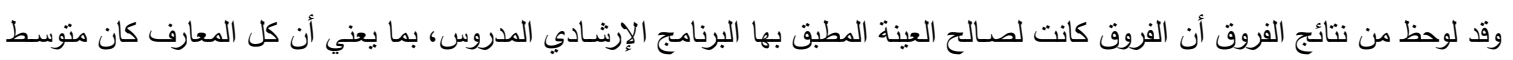

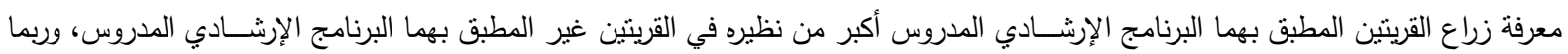
يرجع السبب في ذلك إلى تراكم الخبرات المعرفية لاى زراع الفراولة في القريتين المطبق بهما البرنامج الإرشئادي المدروس.

التعرف علي معنوية الفروق بين متوسطات درجات معارف الزراع المبحوثين بالتوصيات الفنية في مجال زراعة محصول الفراولة لكل من القرى المطبق وغير المطبق بها البرنامج الإرشادي المدروس بمنطقة البحث.

لدراسة معنوية الفروق بين منوسطات درجات معارف زراع الفراولة المبحوثين المتعلقة ببنود نوصياته الفنبة بكل من القرى المطبق وغير

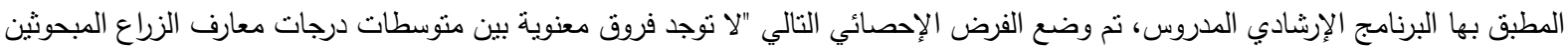
بالتوصيات الفنية في مجال زراعة محصول الفراولة لكل من القرى المطبق وغير المطبق بها البرائ البرنامج الإرشادي المدروس بمنطقة البحث".

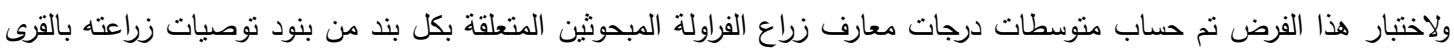
المطبق وغير المطبق بها البرنامج الإرشادي المدروس لهذا المحصول وذلك بإستخدام اختبار (t) لتحديد معنوية الفروق بين كل المتوسطين فكانت

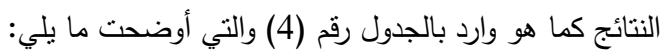

1- وجود فرق معنوي عند مستوى معنوية 0.01 وبين متوسطات درجات معارف زراع الفراولة المبحوثين بكل من القرى المطبق وغير المطبق

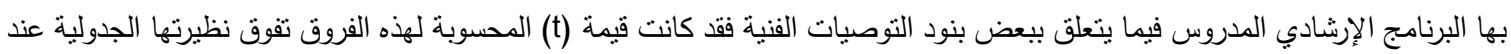

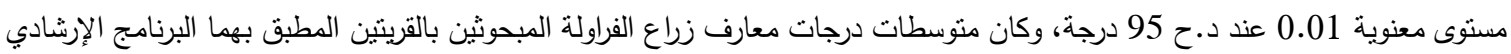

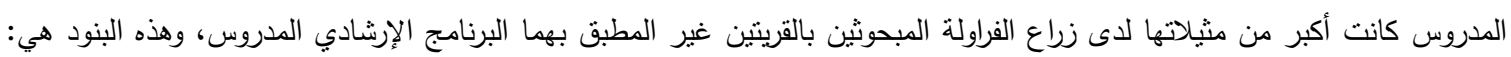

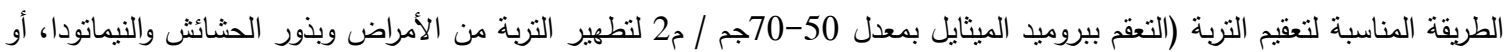


إجراء التعقيم الشمسى للتربة بالبلاستيك الثفاف (رقائق البولى إيثيلين) لدةة شهرين فى يوليو وأغسطس)، والتسميد خلال مرحلة النمو الخضري:

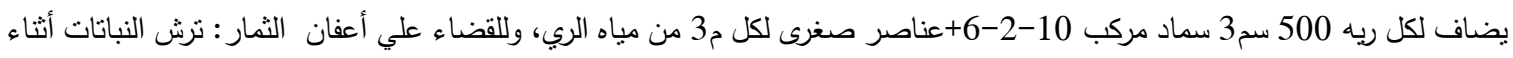

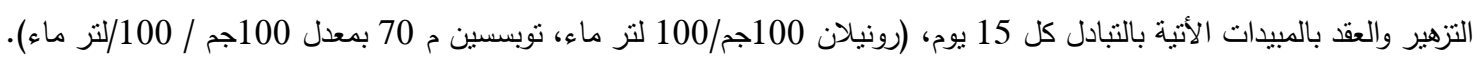

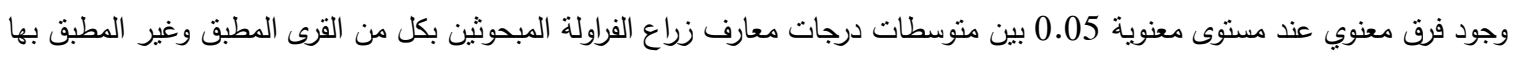

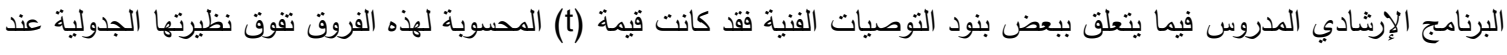

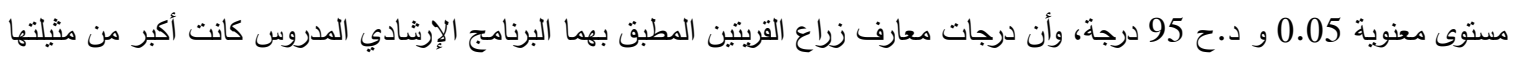

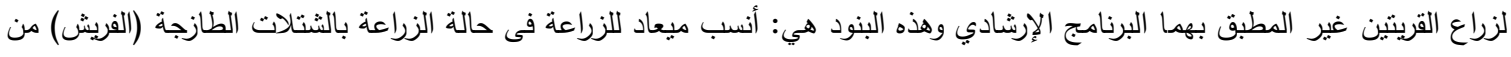

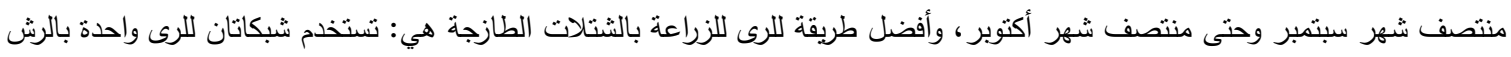

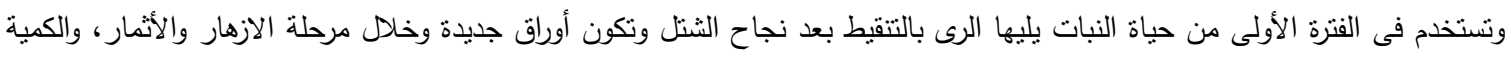

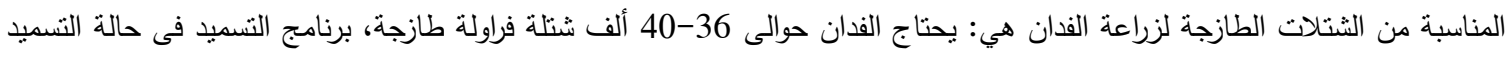

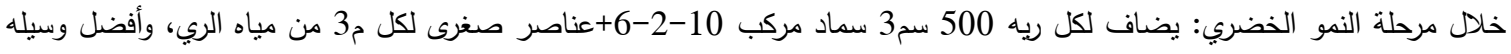

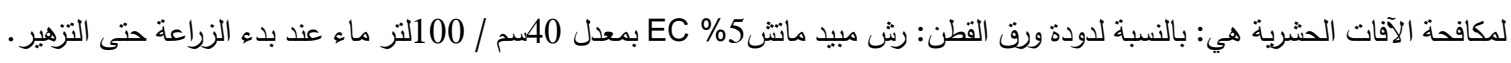

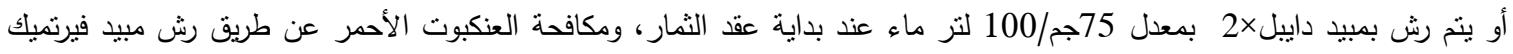

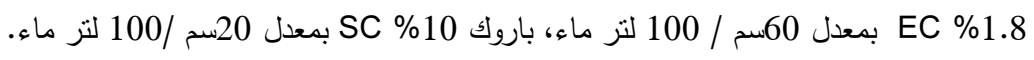

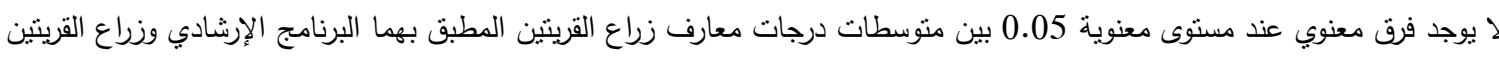

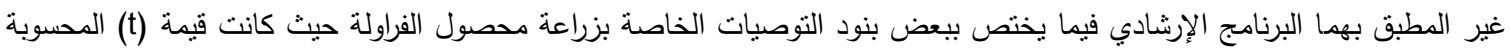

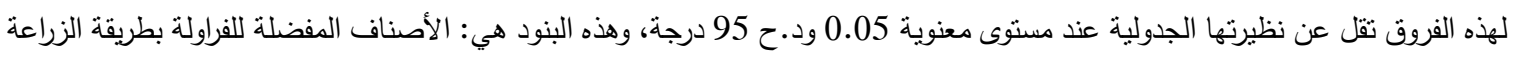

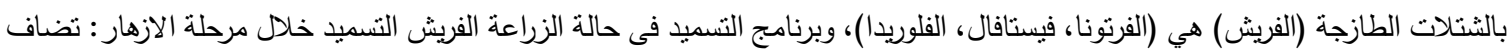
لكل ريه500 سم3 سماد مركب 10-4-8+عناصر صغرى لكل متر مكعب لمياه الري. والتسميد خلال مرحلة الإثمار : يضاف لكل ريه 500

$$
\text { سم3 سماد مركب 8-2-10+عناصر صغرى لكل م3 من مياه الري. }
$$

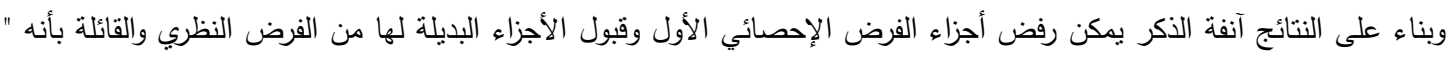

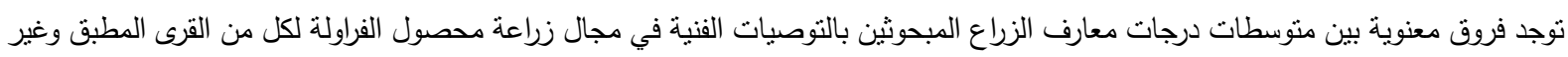

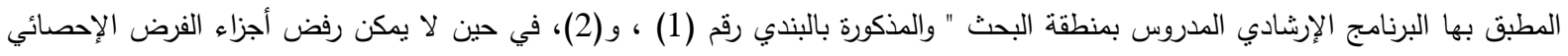

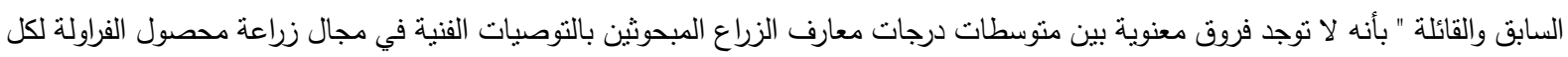

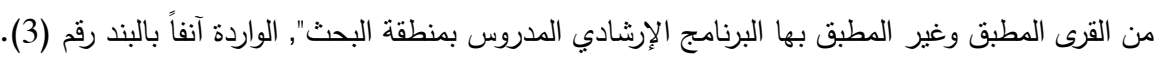

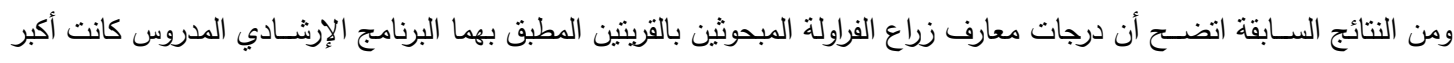

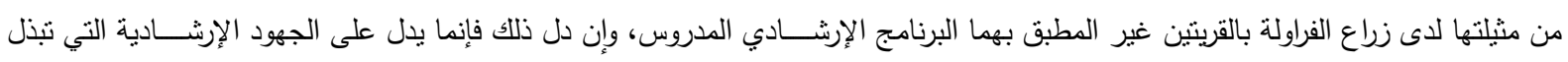

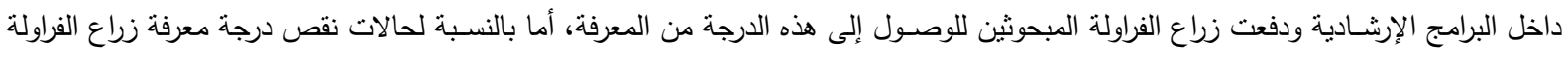

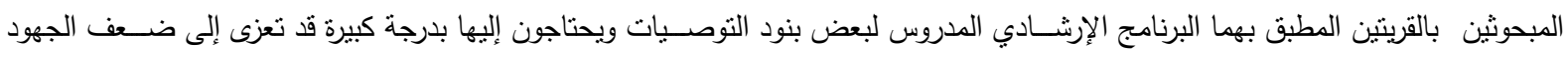

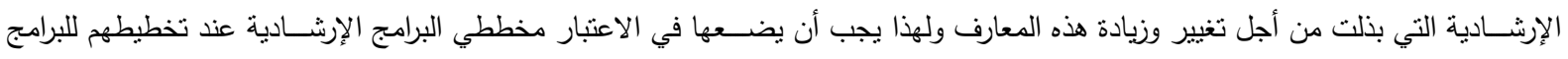

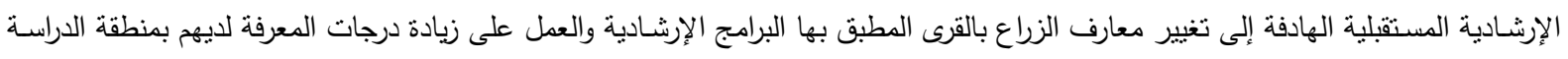
وغيرها من المناطق المشابهة لها. 
هعنوية الفروق بين المتوسطات والانحراف المعياري لدرجات معارف زراع محصول الفراولة المتعلقة ببنود توصياته الفنية بكل من

القرى المطبق وغير المطبق بها البرنامج الإرشادي المدروس بمحافظة القليوبية

\begin{tabular}{|c|c|c|c|c|c|c|}
\hline \multirow{2}{*}{ 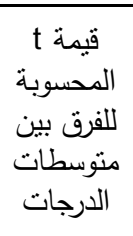 } & \multirow{2}{*}{ 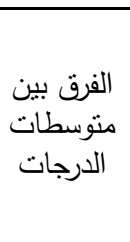 } & \multicolumn{2}{|c|}{ 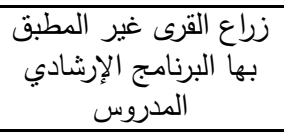 } & \multicolumn{2}{|c|}{ بها البرنامج الإرشادي القريق } & \multirow[b]{2}{*}{ بنود التوصيات } \\
\hline & & 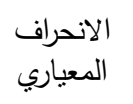 & المتوسط & 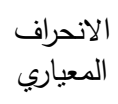 & المتوسط & \\
\hline 1.95 & 0.31 & 0.74 & 1.24 & 0.82 & 1.55 & 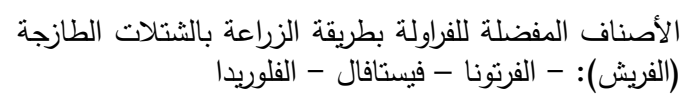 \\
\hline$* 1.98$ & 0.29 & 0.65 & 1.13 & 0.79 & 1.42 & 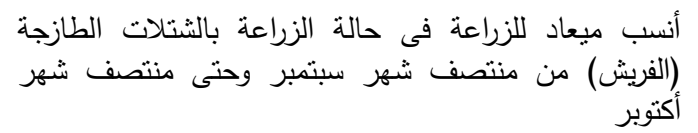 \\
\hline$* * 3.23$ & 0.38 & 0.77 & 1.52 & 0.72 & 1.95 & 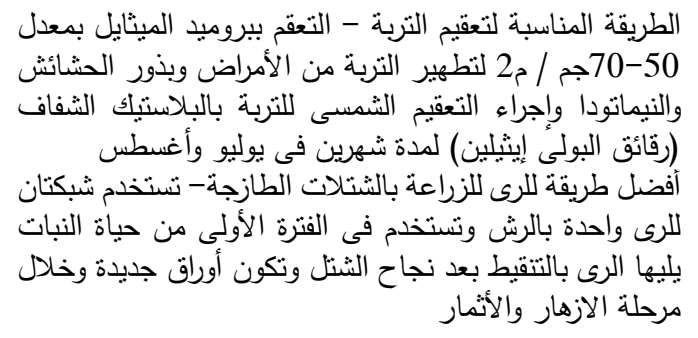 \\
\hline$* 2.28$ & 0.28 & 0.52 & 1.11 & 0.69 & 1.39 & 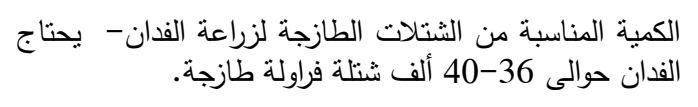 \\
\hline$* * 3.39$ & 0.53 & 0.70 & 1.31 & 0.84 & 1.84 & 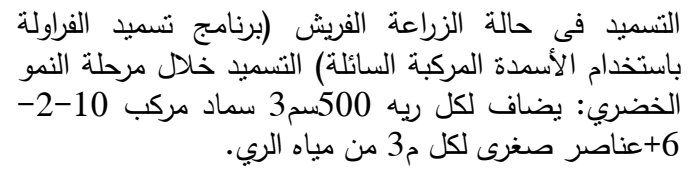 \\
\hline 1.67 & 0.23 & 0.61 & 0.88 & 0.75 & 1.11 & 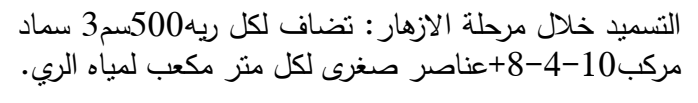 \\
\hline 1.94 & 0.31 & 0.75 & 0.67 & 0.82 & 0.98 & 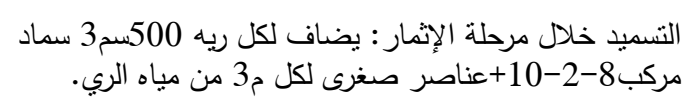 \\
\hline$* 2.25$ & 0.41 & 0.84 & 1.27 & 0.95 & 1.68 & 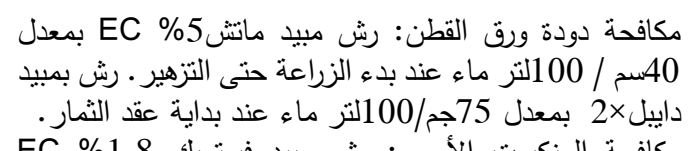 \\
\hline$* 2.52$ & 0.34 & 0.60 & 0.52 & 0.73 & 0.86 & 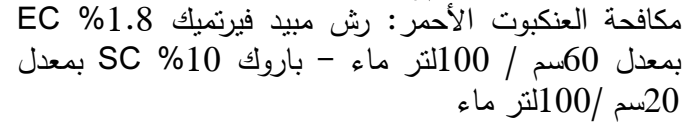 \\
\hline$* * 4.60$ & 0.57 & 0.54 & 1.35 & 0.68 & 1.92 & 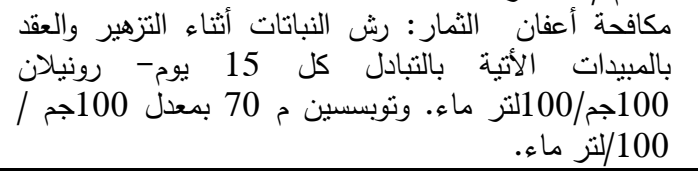 \\
\hline & 4.08 & 7.31 & 12.38 & 8.74 & 16.46 & المجموع الكلي \\
\hline & 0.37 & 0.66 & 1.13 & 0.79 & 1.50 & المتوسط \\
\hline & & & & & : & 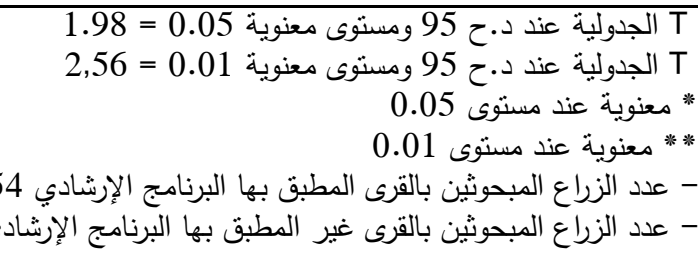 \\
\hline
\end{tabular}


وفي ضوء نتائج البحث النى تم التوصل إليها يمكن النوصية بضرورة اهتمام القائين على العمل الإرشادي الزراعي بمحافظة القليوبية

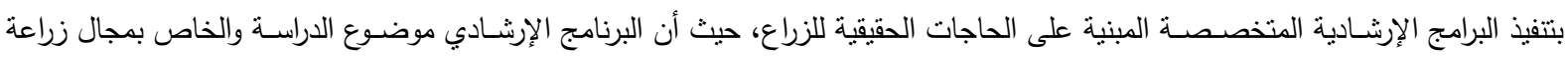

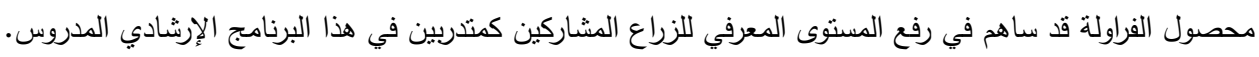

1- الإدارة المركزية للاقتصاد الزراعي ، وزارة الزراعة واستصلاح الأراضي ، بيانات غير منشورة ، الدقي، 2019.

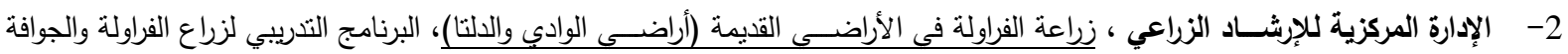

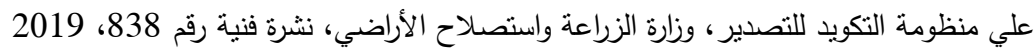
3- رشاد، سعيد عباس محمد رشاد (دكتور)، نقل ونشر التكنولوجيا الزراعية، مكتب الهدي للطباعة والنشر ، مشتهر طوخ، القليوبية، 2016. 4- - سليم، فؤاد كمال (دكتور)، تجربة عملية في التدريب التحويلي للمرشدين الزراعيين في مجال تخطيط البرامج الإرشادية، مجلد مؤتمر مستقبل

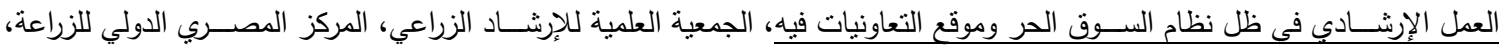
الدقي،1995.

5- - شركة بثـاير، كتيب المشروع التدريبي علي منظومة التكويد للتصديرلزراع الفراولة والجوافة، شركة بثـاير بالتعاون مع قسم المكافحة بوزارة الزراعة، 2019، و 2019.

6- قثــة، عبد الحليم عباس (دكتور)، نحو رؤية اتعزيز الخدمة الإرثـادية الزراعية في مصـر ، مجلد مؤتمر اسـتراتيجية العمل الإرثــادي

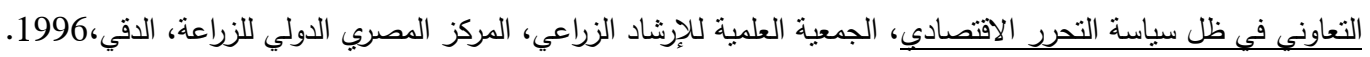

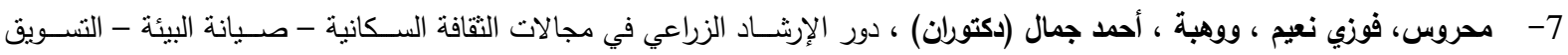
الزراعي ، مجلد مؤتمر استراتيجية العمل الإرشادي التعاونى في ظل سياسة التحرر الاقتصادي ، الجمعية العلمية للإرشاد الزراعي، المركز

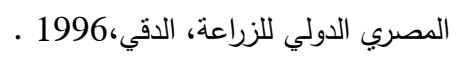
8- مدرية الزراعة بالقليوبية ، قسم الاحصاء، بيانات غير منشورة ، بنها، القليوبية ، 2019. 


\title{
Acquired knowledge of exposing farmers to an extension program in the field of strawberry cultivation in Qalyubia Governorate \\ Prof. Dr. Elsayed Hassan Mohamed Gado * Prof. Dr. Mohamed Amin Sidqi Al Ghawi ** Mahmoud Saied omran $* * *$ \\ * Faculty of Agriculture - Benha University. ** Desert Research Center *** Postgraduate student Corresponding author: alsayed.mustafa@ fagr.bu.edu.eg
}

\begin{abstract}
The research aimed to study the knowledge acquired to expose farmers to an extension program in the field of strawberry cultivation in Qalyubia Governorate, by identifying the degree of knowledge of the farmers researched with the technical recommendations in the field of strawberry cultivation for each of the villages applied and not applied to the extension program studied in the research area, and to determine the degree of change in their knowledge of farmers as a result of exposure to it, and to determine the significant differences between the mean scores of their knowledge with it.

The research was conducted in the two centers of Shebin al-Qanater, and Tookh, as they are the two largest centers in terms of the area in which strawberries are grown in the governorate, and four villages of them were identified with two villages from each center, one of which is from the villages in which the studied extension program is applied, namely the village of Mit Kenana in Toukh center and the village of Kasabiya from the center. Shebin al-Qanater and the other, in which the studied extension program was not applied, namely, the village of al-Deir in the Toukh district and the village of Kafr al-Sahbi in the Shibin al-Qanater center. The search facility was chosen in a systematic, random way by $20 \%$ of strawberry growers in each of the villages that are applied and in which the studied extension program is not applied according to their comprehensive representation. The study sample size was 97 respondents.
\end{abstract}

The research data were collected through a personal interview of the respondents using a questionnaire form during the last three months of 2019 , and the data were analyzed using frequencies, percentages, arithmetic mean, standard deviation and $(\mathrm{t})$ test using the statistical program (SPSS).

The most important results of the research were as follows:

- The total mean of the knowledge scores of the strawberry crop farmers surveyed in the two villages for which the studied extension program was applied was 1.49 points.

- The overall average of the knowledge scores of the strawberry crop farmers surveyed in the two villages in which the studied extension program was not applied was 1.14 points.

- The average difference between the mean knowledge scores of strawberry growers surveyed in the villages applied and not in which the extension program was applied was 0.37 , in favor of the sample in which the extension program was applied.

- The presence of a significant difference at the level of 0.01 significance and between the mean scores of the knowledge scores of strawberry growers surveyed in each of the villages applied and not applied to the extension program studied with regard to some items of technical recommendations. The value of $(t)$ calculated for these differences exceeded its table counterpart at the level of significance 0.01 at $\mathrm{D}$. The mean of the knowledge scores of strawberry growers researched in the two villages in which the studied extension program was applied was greater than that of the strawberry growers surveyed in the two villages where the studied extension program was not applied.

- The presence of a significant difference at a level of 0.05 significance between the mean knowledge scores of strawberry growers surveyed in each of the villages that were applied and not in which the studied extension program was applied with regard to some items of technical recommendations. The value of (t) calculated for these differences exceeded its table counterpart at a significant level of 0.05 and D. The degree of knowledge of the farmers of the two villages in which the extension program was applied was greater than that of the farmers of the two villages in which the extension program was not applied.

- There is no significant difference at the 0.05 level of significance between the mean knowledge scores of the farmers of the two villages in which the extension program is applied and the village farmers in which the extension program is not applied with regard to some items of recommendations for planting strawberry crops, where the value ( $\mathrm{t}$ ) calculated for these differences is less than its table counterpart at the level of The significance of 0.05 , and D.h 95 degree.

In light of the results of the research that have been reached, it can be recommended that those in charge of agricultural extension work in Qalyubia governorate should pay attention to the implementation of specialized extension programs based on the real needs of farmers, as the extension program in question in the field of strawberry cultivation has contributed to raising the level of knowledge of participating farmers as trainees in this well thought out extension program. 